\title{
Steady State Analysis and Impact of Benban Solar Park on The Egyptian Transmission System
}

\author{
Mohammed Fawzy Ibrahim ${ }^{1}$, Prof. Dr. Sayed A. Ward ${ }^{2}$, Prof. Dr. Fahmy Bendary ${ }^{3}$, Dr. Mahmoud Omar ${ }^{4}$ \\ ${ }^{1}$ Egyptian Electricity Transmission Company (EETC), Egypt, eng.mohamedfawzy92@ gmail.com \\ ${ }^{2}$ Faculty of Engineering (Shoubra)Benha University,Faculty of Engineering Delta University for Science and Technology, \\ Egypt, drsayedw@yahoo.com \\ ${ }^{3}$ Faculty of Engineering (Shoubra)Benha University, Egypt, fahmybendary10@ gmail.com \\ ${ }^{4}$ Faculty of Engineering (Shoubra) Benha University, Egypt, engmahmoudomar_10@yahoo.com
}

\begin{abstract}
Egypt is progressing from a power system with old traditional thermal power stations to a cutting-edge power system with a profoundly productive combined cycle power plants (Siemens $14.4 \mathrm{GW}$ power plants) and an expanding portion of sustainable power sources. By 2022, Egypt intends to produce $20 \%$ of its power from renewables [1]. Benban Solar Park venture is considered as the world's largest solar power plant, with total capacity of about $1.8 \mathrm{GW}$. The large renewable power stations, especially the solar power plants, have a significant effect on power systems stability due to rapid and large fluctuations in power generation caused by various factors such as the intermittency of solar irradiance, climate change and tripping out of power electronic based converters connected to the system.

This paper presents the specialized technical details of the assessment and results to ensure that the Egyptian Transmission System (ETS) is capable to evacuate the renewable power in safe manner under various operating conditions
\end{abstract}

Abbreviations
\begin{tabular}{|l|l|}
\hline GW & Giga watt \\
\hline ETS & Egyptian transmission system \\
\hline UAE & United Arab Emirates \\
\hline PV & Photovoltaic \\
\hline KSA & Kingdom Saudi Arabia \\
\hline MW & Mega watt \\
\hline KV & Kilo volt \\
\hline PSS/E & Power system simulator for engineers \\
\hline NREA & New and renewable energy authority \\
\hline EETC & Egyptian electricity transmission company \\
\hline PK & Peak \\
\hline MPK & Morning peak \\
\hline ACSR & Aluminum Conductor Steel Reinforced \\
\hline STACIR & Sterlite Super Thermal Alloy Conductor Invar Reinforced \\
\hline PU (pu) & Per unit \\
\hline MVA & Mega volt ampere \\
\hline A & Ampere \\
\hline CKT & Circuit \\
\hline MVAR & Mega volt ampere reactive \\
\hline QV & Reactive power versus voltage analysis \\
\hline MSSP & Medium scale solar plant \\
\hline LSSP & Large scale solar plant \\
\hline EGP & Egyptian pound \\
\hline (D/Cs) & Double circuits \\
\hline TL & Transmission line \\
\hline
\end{tabular}

Key Words: Benban Solar park - Egyptian Transmission System - Steady State Analysis - PSS/E (Power System Simulator for Engineers) - PV photovoltaic. 


\section{INTRODUCTION}

In the first half of the year 2019, positive signs are showing up on the worldwide solar based market. The worldwide solar market will at last surpass 100 gigawatts in 2019, with Wood Mackenzie's most recent 2019 forecast beating at 103 gigawatts. The main 20 biggest worldwide PV markets will represent 83 percent of new world demand to 2023, the quickest developing of which are located in the Middle East and Mediterranean (Saudi Arabia, Iran, Egypt, and Italy)[2]. Leading countries of the Middle East and North Africa region are steadily dispatching enormous ventures and developing extra phases of their renewable energy and solar programs (Morocco, Egypt and the UAE) and other countries of the region are coming on board[3]. Renewable energy integration has been growing significantly globally over the last year. This trend will proceed to increase as solar power prices reach grid parity. In 2019, the worldwide estimated additions of solar photovoltaic (PV) reached around $100 \mathrm{GW}$ [4].

Wind and Solar energy are believed to be cost-effective, accessible to every-one and environ-mentally friendly. For example, in Jordan and due to the Jordanian wealth of sustainable energy source assets, wind and solar electricity production can meet a gigantic portion of the daily power demand[5]. And for KSA is located between latitude $17.5 \mathrm{~N}$ and latitude $31 \mathrm{~N}$ places inside the Sun Belt extending 40 to the north of the Equator. This is exceptionally advantageous for KSA's potential prospects in solar energy as it permits extraordinary amounts of solar irradiance. The solar radiation averages between at least $4.479 \mathrm{kWh} / \mathrm{m}^{2}$ and $7.004 \mathrm{kWh} / \mathrm{m}^{2}$, measured at Tabuk and Bisha respectively. Southern cities other than Bisha like Sulayyil and Nejran will of course have much more solar radiation[6].

Egypt's growing economy and population require a dependable electricity source which can face the rapidly expanding demand. In the last years, this increase results in blackouts as the generating capacity could not meet the loads. The increased demand has also led to pressure on Egypt's gas sources and reserves. Hence, significant extra capacity is required every year[7]. Energy production, enhancement and simplicity of dealing with are considered the principal axes of development. The Egyptian energy policies and legislation agree with the consumption pattern and empower the execution of renewable energy sources, targeting generating $20 \%$ of electricity in Egypt by 2022 from inexhaustible energy sources with the dynamic interest of the private sector in this program[1].

Solar and wind the most significant sources of sustainable energy, are available in abundance in Egypt. The availability of solar irradiance everywhere throughout the year with global solar radiation is between 5 and $8 \mathrm{kwh} / \mathrm{m} 2 /$ day. Accordingly, 5 to $13 \mathrm{~m} / \mathrm{s}$ wind speed is needed, which is available in Egypt in various areas, for example, Zafarana, Al-Arish, MarsaMatrouh and Khargha. Zafarana wind farm has a very significant and dynamic environmental impact to gain an amount of energy of about $600 \mathrm{MW} / \mathrm{year}[8]$. As per Egypt's Wind Atlas [9], [10], the country is blessed with rich wind energy resources, especially in the Gulf of Suez area. This is perhaps the best area on the planet for utilization of wind energy because of its high steady wind speeds that reach on average between 8 and $10 \mathrm{~m} / \mathrm{s}$ at a height of 100 meters. In addition, promising new regions have been found east and west of the Nile river in the Beni Suef and Menya Governorates and El Kharga Oasis in the New Valley Governorate. They have wind speeds that shift somewhere in the range of 5 and $8 \mathrm{~m} / \mathrm{s}$ and are reasonable for electricity production[11].

In this paper, the steady state assessment will be performed to the Egyptian electricity transmission system with Benban solar park to assess the network performance and to ensure that the generated power will be evacuated in safe manner. the proposed stage of Benban solar park generation evacuation is to evacuate of about $1000 \mathrm{MW}$ by means of connecting the park to the $220 \mathrm{KV}$ transmission network. The used model is the verified model of the Egyptian national grid for the year 2019 using the SIEMENS verified software PSS/E. This paper presents the Egyptian electricity transmission system, deep knowledge of Benban solar park, and steady state enhancement results.

\section{THE EGYPTIAN TRANSMISSION SYSTEM:}

The Arab Republic of Egypt is investing heavily into the electricity sector in both traditional power stations, e.g., with the "Siemens megaproject" including three gas-fired combined cycle plants with a total of $14.4 \mathrm{GW}$ capacity, and transmission and distribution networks, and also in power generation from sustainable energy sources, i.e., wind and PV capacity. Large number of $\mathrm{PV}$ and wind projects are in operation, construction or planning phases. It is targeted to produce $20 \%$ of all electricity in Egypt from renewables by 2022. In the last five years, the average growth rate of the peak load is $4.2 \%$ per year [12]. The peak load in summer 2013/2014 was 26140 MW recorded in 6/8/2013[13], while in summer 2014/2015 was 28015 MW recorded in 12/8/2014[14]. The peak load in summer 2015/2016 was 29200 MW obtained on 16/8/2015[15], summer $2016 / 2017$ was $29400 \mathrm{MW}$ recorded in $2 / 8 / 2016[16]$ and summer 2017/2018 was 30800 MW recorded in $13 / 8 / 2017[12]$ and summer 2018/2019 was 31400 recorded in 25/7/2018 [17]. Figure 1 shows the Egyptian transmission grid and Figure 2 shows the peak demand development over the last seven years.

\section{BENBAN SOLAR PARK:}

The project includes the construction and operation of 40 individual PV electricity generating facilities as shown in Figure 3, located on an area of approximately 37.2 square kilometers near the village of Benban in Aswan Governorate in Upper Egypt. The New and Renewable Energy Authority (NREA), which owns the site, is making the 40 lots of between 0.3 and $1.0 \mathrm{~km}^{2}$ available to developers who will construct individual solar PV electricity generating facilities[18].

The Benban PV power plant site is situated in the western desert, around $650 \mathrm{~km}$ south of Cairo and $40 \mathrm{~km}$ northwest of Aswan city. It is inside Aswan Governorate. The area assigned for the project is desert land possessed by NREA. Table 1 shows the site coordinates and Figure 4 show the location of the site. 


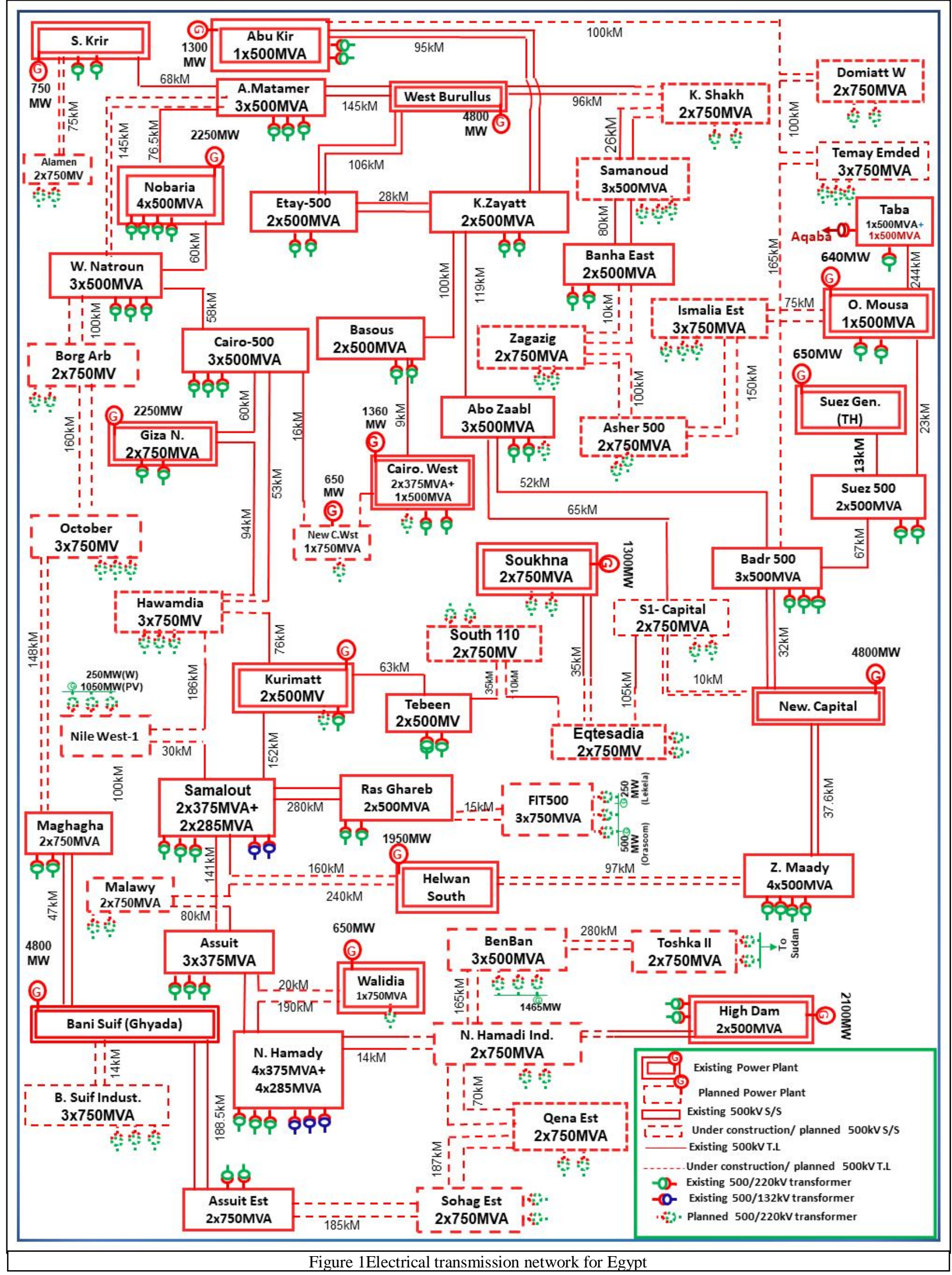


Mohammed Fawzy Ibrahim et al., International Journal of Advanced Trends in Computer Science and Engineering. 10(2). March - April 2021, 928 - 940

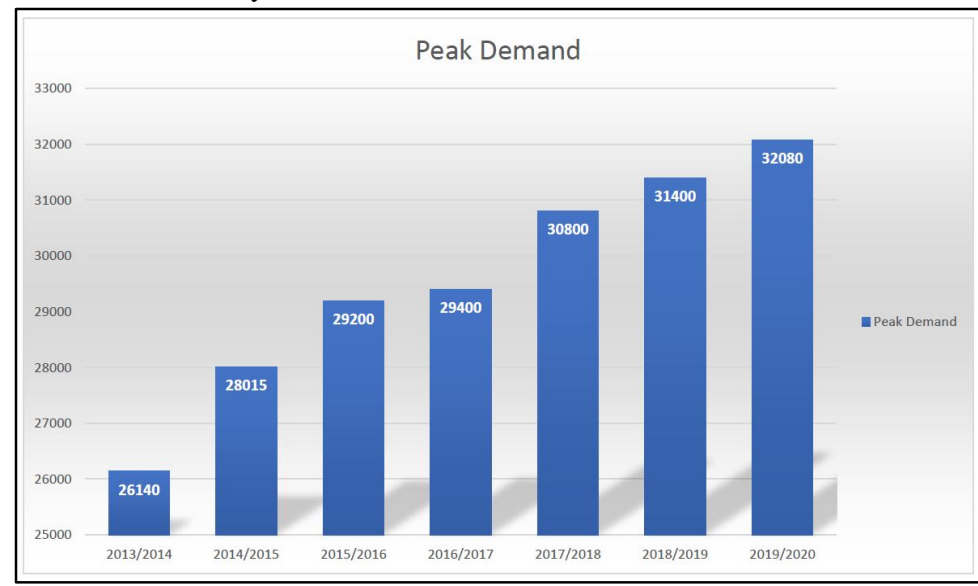

Figure 2Egyptian peak demand development

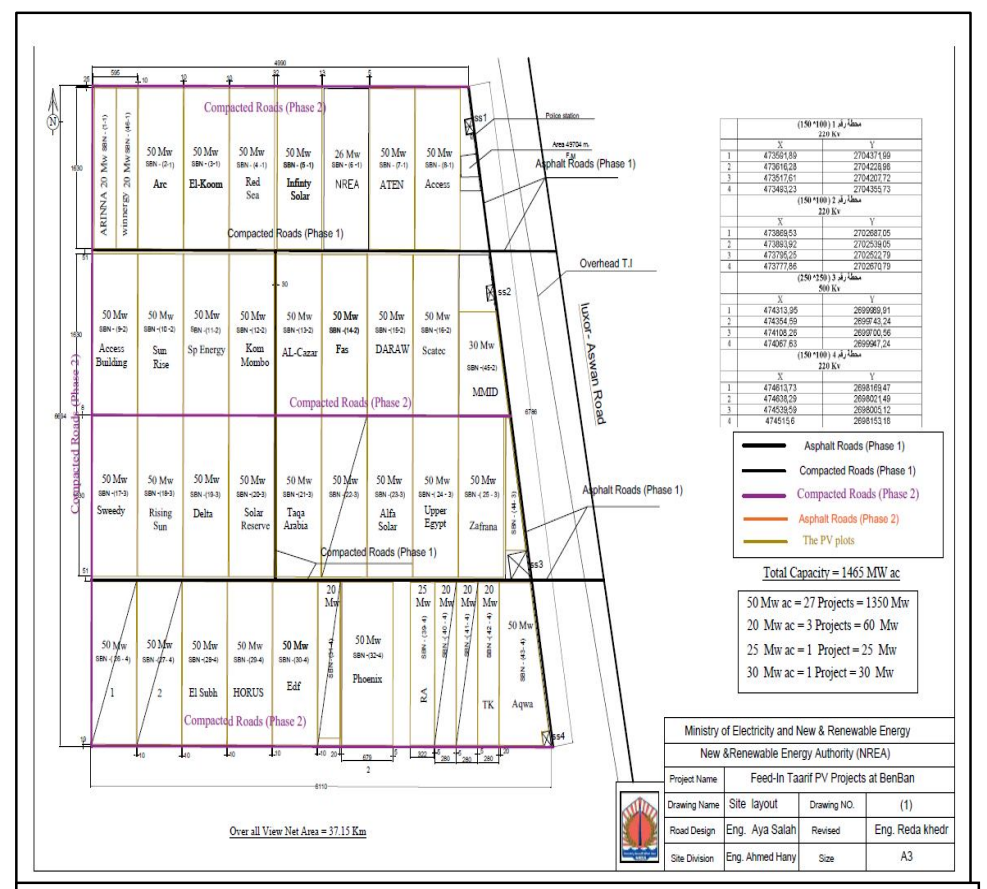

Figure 3 Benban individual lots

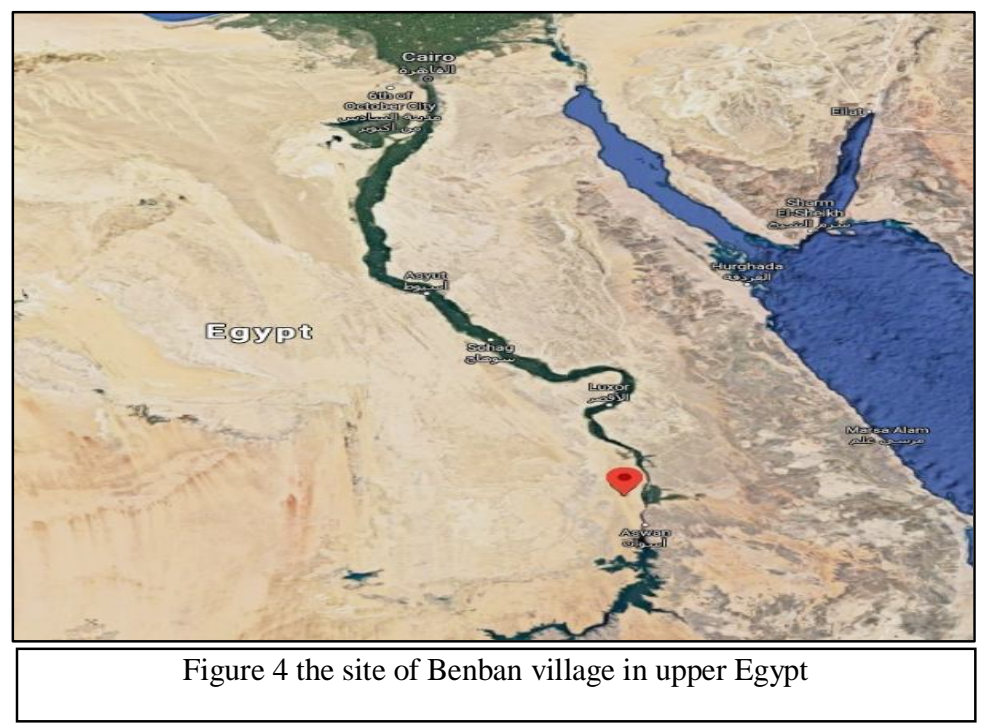

Table 1Benban site coordinates

\begin{tabular}{|c|c|c|}
\hline Point & Near & Longitude \\
\hline $\mathbf{1}$ & $2^{\circ} 27^{\prime} 21.563^{\prime \prime} \mathrm{N}$ & $32^{\circ} 44^{\prime} 20.364^{\prime \prime} \mathrm{E}$ \\
\hline $\mathbf{2}$ & $2^{\circ} 23^{\prime} 41.999^{\prime \prime} \mathrm{N}$ & $32^{\circ} 44^{\prime} 52.799^{\prime \prime} \mathrm{E}$ \\
\hline $\mathbf{3}$ & $2^{\circ} 23^{\prime} 41.964^{\prime \prime} \mathrm{N}$ & $32^{\circ} 41^{\prime} 23.964^{\prime \prime} \mathrm{E}$ \\
\hline $\mathbf{4}$ & $24^{\circ} 27^{\prime} 21.563^{\prime \prime} \mathrm{N}$ & $32^{\circ} 41^{\prime} 23.964^{\prime \prime} \mathrm{E}$ \\
\hline
\end{tabular}

\section{STEADY STATE ENHANCEMENT:}

\subsection{The grid study model}

The study is performed on the Egyptian network model of the year 2019 including the Siemens mega project power plants and including the wind farms at Zafarana and Gabal El Zeit.

The study is implemented by means of the certified SIEMENS software PSS/E ver. 33 (Power System Simulator for Engineers), the steady state study is proposed using the available data using the Egyptian transmission network model.

The study model includes the following renewable energy projects in service:

1.Zafarana 1,2 wind farms with power generated about 547 MW

2. Gabal Al Zeit wind farm with power generated about 612 MW

3. Toyota Ras Ghareb wind farm with power generated about $250 \mathrm{MW}$

4. Benban solar park with power generated about $1800 \mathrm{MW}$

The daily generation cycle measurement, of a single site PV generator, in Benban site, which is in operation, is scaled up to $1800 \mathrm{MW}$ to get the total generation cycle and it is coincided with the network demand load curve on the same graph as shown in Figure 5 (load curve vs PV generation). it is clear that the maximum generation point occurs steadily between 10:00 $\mathrm{AM}$ and 11:00 AM and the most severe point which considering the most stressful point of the grid is at $11.00 \mathrm{AM}$ at which the generation of the solar park is steadily maximum and the network demand is nearly close to its peak. As the absolute maximum and minimum hours of the network demand occur outside the effective day light, the selected point is at which the two peaks (peak of PV generation and peak of the grid demand) are coinciding.

\subsection{Study Criteria, Assumptions and Alternatives:}

\subsubsection{System Security Requirements}

According to the last update of the Egyptian Electricity Transmission company (EETC) Grid Code[19]-[22], the following contingency events are considered:

"The Transmission System shall be planned and operated according to the (n-1) criterion, and as deemed needed and justified by the transmission system operator shall be planned and operated according to the (n-2) criterion."

$(\mathrm{N}-1)$; Disconnecting one element of the $500,220 \mathrm{kV}$ network (line or transformer).

(N-2); As deemed needed

\subsubsection{Study Assumptions}

The study is conducted taking into consideration the following assumptions

1) Maximum demand (PK) is $32080 \mathrm{MW}$ 
2) Morning Peak (MPK) demand is 28800 MW (about $90 \%$ of Max. demand)

3) Maximum installed renewable power is $3209 \mathrm{MW}$.

- $\quad$ Maximum considered wind generation is about 1409 MW.

- Maximum considered PV generation is about $1800 \mathrm{MW}$.

4) All generator units are capable to operate according to their capability curves

5) The tap changer of the tie-transformer can be changed to adjust the voltage levels of the network.

6) For the preliminarily study, the Benban generators are operating at unity power factor.

7) The contingency analysis condition is on (N-1) condition for a single component (Circuit or Transformer or Generator) in the system.

\subsubsection{Study Stages:}

The study conducted based on the evacuation of about 1000 MW as a preliminary stage

\subsubsection{Alternatives of Stage 1:}

- Alternative 1:opening the double circuit OHTL $220 \mathrm{kV}$, (ACSR 2*380/50 $\mathrm{mm}^{2}$ ) (selwa /W. Nokra /A.dam) line in/out on the Benban solar park substations.

- Alternative 2:opening the double circuit OHTL $220 \mathrm{kV}$ (selwa /W. Nokra /A.dam) line in/out on the Benban solar park substations after rehabilitating its conductors to be bundle of three (ACSR $3 * 380 / 50 \mathrm{~mm}^{2}$ ).

- Alternative 3:opening the double circuit OHTL $220 \mathrm{kV}$ (selwa /W. Nokra /A.dam) line in/out on the Benban solar park substations after replacing its conductors with thermal conductors of type (Thermal STACIR $2 * 238 / 97 \mathrm{~mm}^{2}$ ), and Figure 6 shows different alternatives topology.

The main difference between the three alternatives is the conductor type and its current capacity as the (Aluminum

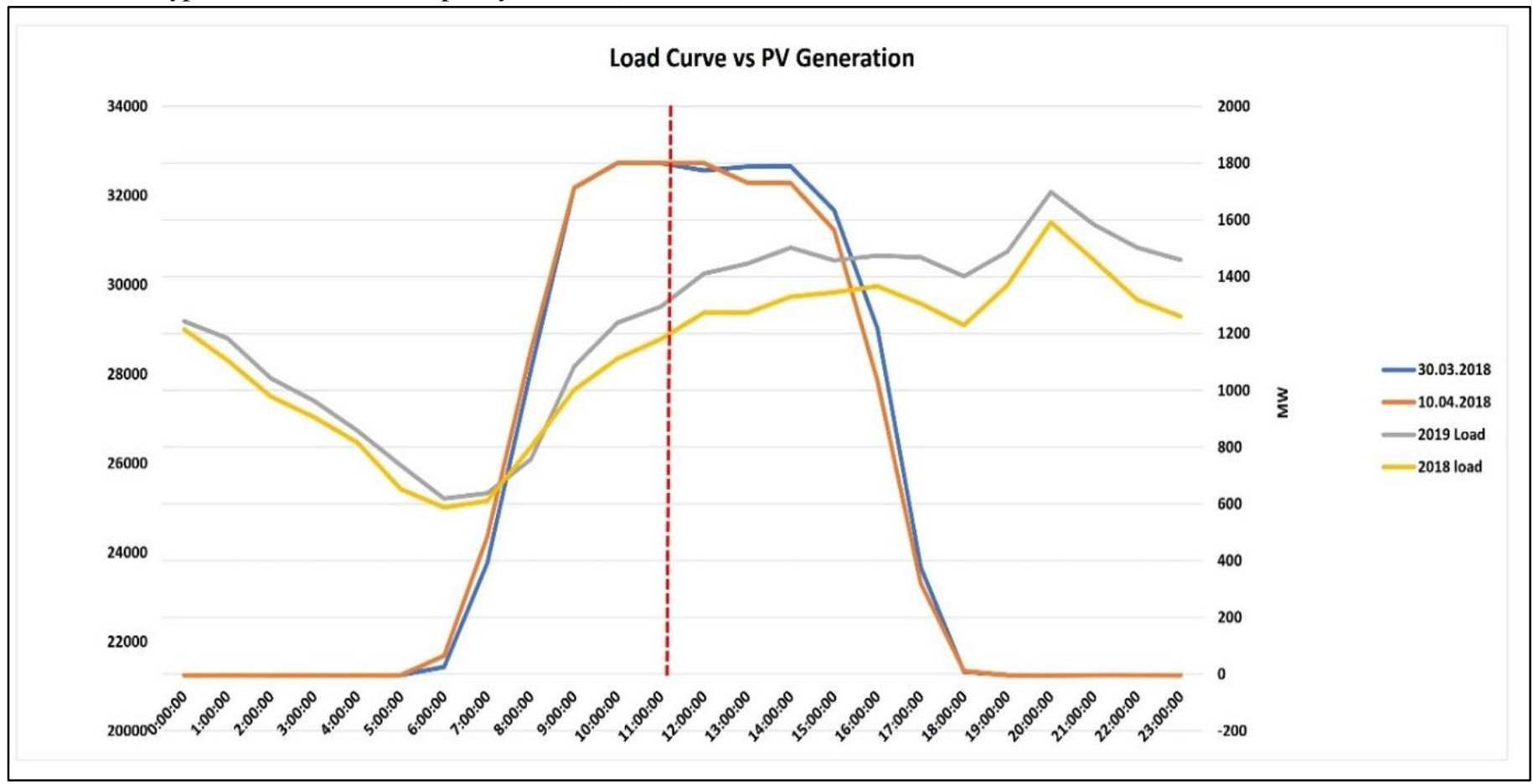

Figure 5 load curve vs PV generation pattern

Conductor Steel Reinforced) ACSR $1 * 380 / 50 \mathrm{~mm}^{2}$

conductor can carry up to $600 \mathrm{Amps}$, where the bundle of two ACSR $2 * 380 / 50 \mathrm{~mm}^{2}$ affords up to 1200 Amps and 1800 Amps for the bundle of three ACSR $3 * 380 / 50 \mathrm{~mm}^{2}$ but the current carrying capacity increases to be 2400 Amps in case of using thermal conductors such as (Sterlite Super Thermal Alloy Conductor invar Reinforced) STACIR $2 * 238 / 97 \mathrm{~mm}^{2}$

The current capacity affects directly the MVA rating of the conductor, Table 2 shows the electrical specifications of the used conductors in addition to the weight of each type in $\mathrm{kg} / \mathrm{km}$. 


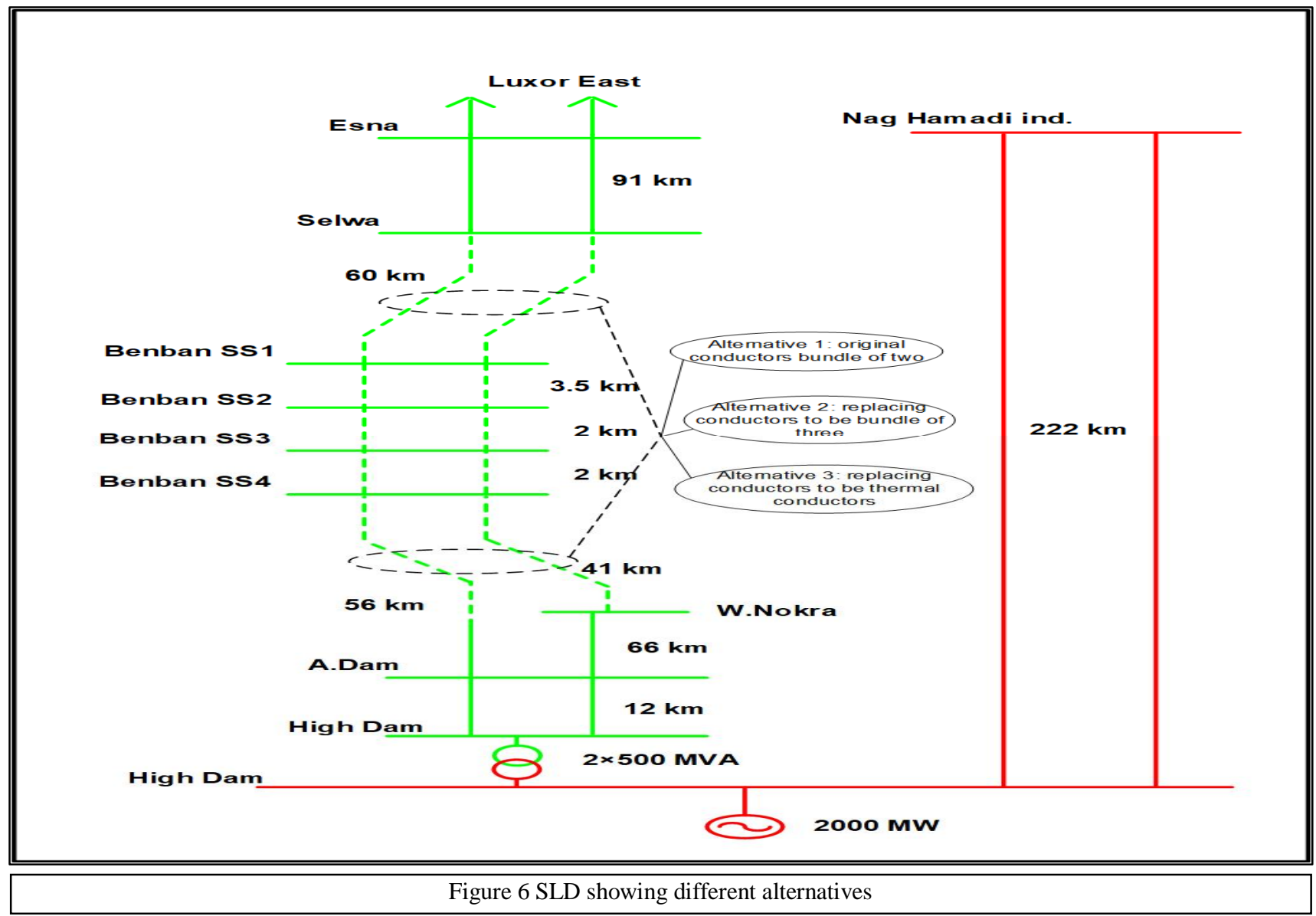

Table 2Parameters of the used conductors

\begin{tabular}{|c|c|c|c|c|c|c|}
\hline Type & $\begin{array}{c}\text { Current } \\
\text { capacity } \\
(\mathbf{A})\end{array}$ & $\begin{array}{c}\text { Rate } \\
(\text { MVA) }\end{array}$ & $\begin{array}{c}\text { Resistance } \\
(\mathbf{P U})\end{array}$ & $\begin{array}{c}\text { Reactance } \\
\text { (PU) }\end{array}$ & $\begin{array}{c}\text { Wharging } \\
\text { (PU) }\end{array}$ & $\begin{array}{c}\text { Weight of } \\
\text { conductor } \\
(\mathbf{k g} / \mathbf{k m})\end{array}$ \\
\hline ACSR 2*380/50 $\mathrm{mm}^{2}$ & 1200 & 457 & 0.0000851 & 0.000624 & 0.0018 & 2906 \\
\hline ACSR 3*380/50 mm & 1800 & 685 & 0.00004483 & 0.0006095 & 0.00191664 \\
\hline $\begin{array}{c}\text { Thermal STACIR } \\
2 * 238 / 97 \mathrm{~mm}^{2}\end{array}$ & 2400 & 914 & 0.00011831 & 0.0006975 & 0.001628726 & 2889.64 \\
\hline
\end{tabular}




\subsection{Results of stage 1:}

\subsubsection{Alternative 1:}

The morning peak scenario is tested for normal operation conditions $(\mathrm{N}-0)$ and the results show that there is no overloading in the normal condition but, there are some minor voltage violations at Esna and Selwa substations as the voltages reach to $0.94 \mathrm{pu}$ (about $206 \mathrm{kV}$ ). Also, the contingency analysis (N-1) is conducted and results show that the main bottlenecks, due to Benban integration, are observed in the $220 \mathrm{kV}$ network as follows:

1. In case of (N-1) of the $220 \mathrm{kv}$ circuit (W. nokra/Benban SS4), the circuit (Benban SS4/A. dam) loading reaches about $108 \%$

2. In case of (N-1) of one circuit of the double circuit $220 \mathrm{kV}$ OHTL of (Selwa/Benban SS1), the other circuit loading reaches about $106 \%$.

3. In the case of (N-1) of the $220 \mathrm{kv}$ circuit (W. nokra/A. dam), the circuit (Benban SS4/A. dam) loading reaches about 92\%, and severe voltage violation of $0.87 \mathrm{pu}$ and $0.89 \mathrm{pu}(192 \mathrm{kv}$ and $195 \mathrm{kv}$ ) is obtained at W. nokra and Selwa respectively.

4. A voltage of $0.89 \mathrm{pu}(196 \mathrm{kv})$ is obtained at Esna in different (N-1) cases (Nag. Hamadi Ind./ Qena south $220 \mathrm{kv}$ ) and (High Dam/ Nag. Hamadi Ind. 500 kv).

5. The critical contingency event (N-1) of the $220 \mathrm{kv}$ circuit (Benban SS4/A. dam) causes system blown up.

6. The critical contingency event $(\mathrm{N}-1)$ of one $500 / 220 \mathrm{kV}$ transformer at High dam substation causes asystem blown up.

Based on the above, it is clear that this alternative is not satisfying the grid code requirements and has a lot of under voltage and over loading violations so that it is necessary to propose another alternative which will be able to overcome the violations and improve system reliability.

\subsubsection{Alternative 2:}

In this alternative, the conductors of the OHTL (Selwa /W. Nokra /A.dam) will be replaced to be bundle of three (ACSR $3 * 380 / 50 \mathrm{~mm}^{2}$ ) with the capacity of 685MVA.The results for $(\mathrm{N}-0)$ in this alternative are similar to these of the last alternative. The morning peak scenario is examined for normal operation conditions $(\mathrm{N}-0)$. The results show that there is no overloading in the normal condition but, there are also some minor voltage violations at Esna and Selwa substations as the voltages reach to 0.94 pu (about $206 \mathrm{kV}$ ).

The contingency analysis (N-1) is conducted and the results show that the main bottlenecks appeared in the first alternative are eliminated here as follows:

1. In case of (N-1) of the $220 \mathrm{kv}$ circuit (W. nokra/Benban SS4), the circuit (Benban SS4/A. dam) loading decreases from $108 \%$ to $74 \%$

2. In case of (N-1) of one circuit of the double circuit $220 \mathrm{kV}$ OHTL of (Selwa/Benban SS1), the other circuit loading is reduced by about $35 \%$ (i.e. from $106 \%$ to $71 \%$ )

3. In the case of (N-1) of the $220 \mathrm{kv}$ circuit (W. nokra/A. dam), the circuit (Benban SS4/A. dam) loading decreases from $92 \%$ to $62 \%$, and still there is severe voltage violation of $0.87 \mathrm{pu}$ and $0.89 \mathrm{pu}(192 \mathrm{kv}$ and $195 \mathrm{kv})$ is obtained at $\mathrm{W}$. nokra and Selwa respectively.
4. Still also there are a voltage violation of $0.89 \mathrm{pu}(196 \mathrm{kv})$ is obtained at Esna in the (N-1) case of (Nag. Hamadi Ind./ Qena south $220 \mathrm{kv}$ ).

5. The critical contingency event (N-1) of the $220 \mathrm{kv}$ circuit (Benban SS4/A. dam) still causes system blown up.

6. The critical contingency event $(\mathrm{N}-1)$ of one $500 / 220 \mathrm{kV}$ transformer at High dam substation still also causes system blown up.

Based on the above, it is seen obviously that this alternative is satisfying the grid code requirements with respect to the equipment's loading only but it has a lot of voltage violations so that it is necessary to propose a mitigation measure to overcome the voltage violations.

We can see that this alternative reliefs the overloading conditions, but still we have some under voltage violations which may be solved by mans of reactive power compensation specially because in our case, the under-voltage violations appear not only, in the contingency cases $(\mathrm{N}-1)$ but also, in the normal conditions (N-0).

\subsubsection{Reactive power requirement study $(\mathrm{QV}$ - Analysis) for alternative 2:}

The QV-analysis is performed at several buses to obtain the optimum amount of MVAR to overcome the under-voltage violations in both normal and different contingency cases. Three buses are selected to perform $\mathrm{QV}$-analysis at each:

1. Bus 5200 Benban SS2

2. Bus 508 Selwa

3. Bus 5400 Benban SS4

The results will be applied at only one bus from the above buses not all of them. It is clear from the contingency analysis results of alternative two that there are some critical contingency cases. So that, the $\mathrm{QV}$-analysis is performed to overcome the under-voltage violations in both normal and different contingency cases for all possible contingencies for the nearby substations of Benban solar park. The main focus will be on the critical contingency cases which are responsible for the blown-up cases and severe under voltage violations such:

1. Disconnect one of 500/220kV transformers of High Dam SS

2. Disconnect one 220kV Ckt of (Benban SS4/A. Dam)

3. Disconnect one $500 \mathrm{kV}$ Ckt of (High Dam/Nag. Hamadi ind.)

4. Disconnect one 220kV Ckt of (Nag. Hamadi ind./S. Qena)

Based on the above to overcome the under-voltage violations at Benban solar park nearby substations during normal and different contingency cases, reactive power support is required with the value of:

1. $200 \mathrm{MVAR}$ at bus 5200 (Benban SS2) or

2. 200 MVAR at bus 5400 (Benban SS4) or

3. 210 MVAR at bus 508 (Selwa), Table 3 shows the QVanalysis results and Figure 7 shows also the results.

This reactive power could be obtained by several methods such:

1. Reactive power compensators

2. MVAR from generators

The reactive power compensators like capacitor banks and static var compensators are very expensive. However, Benban generation is considered to be a source of reactive power if the units are working as per the solar code[23]. The solar Egyptian grid code is asking the solar power facility to support the grid needs of the reactive power. The solar plant should have the ability to generate active power with 
Study bus: 5200

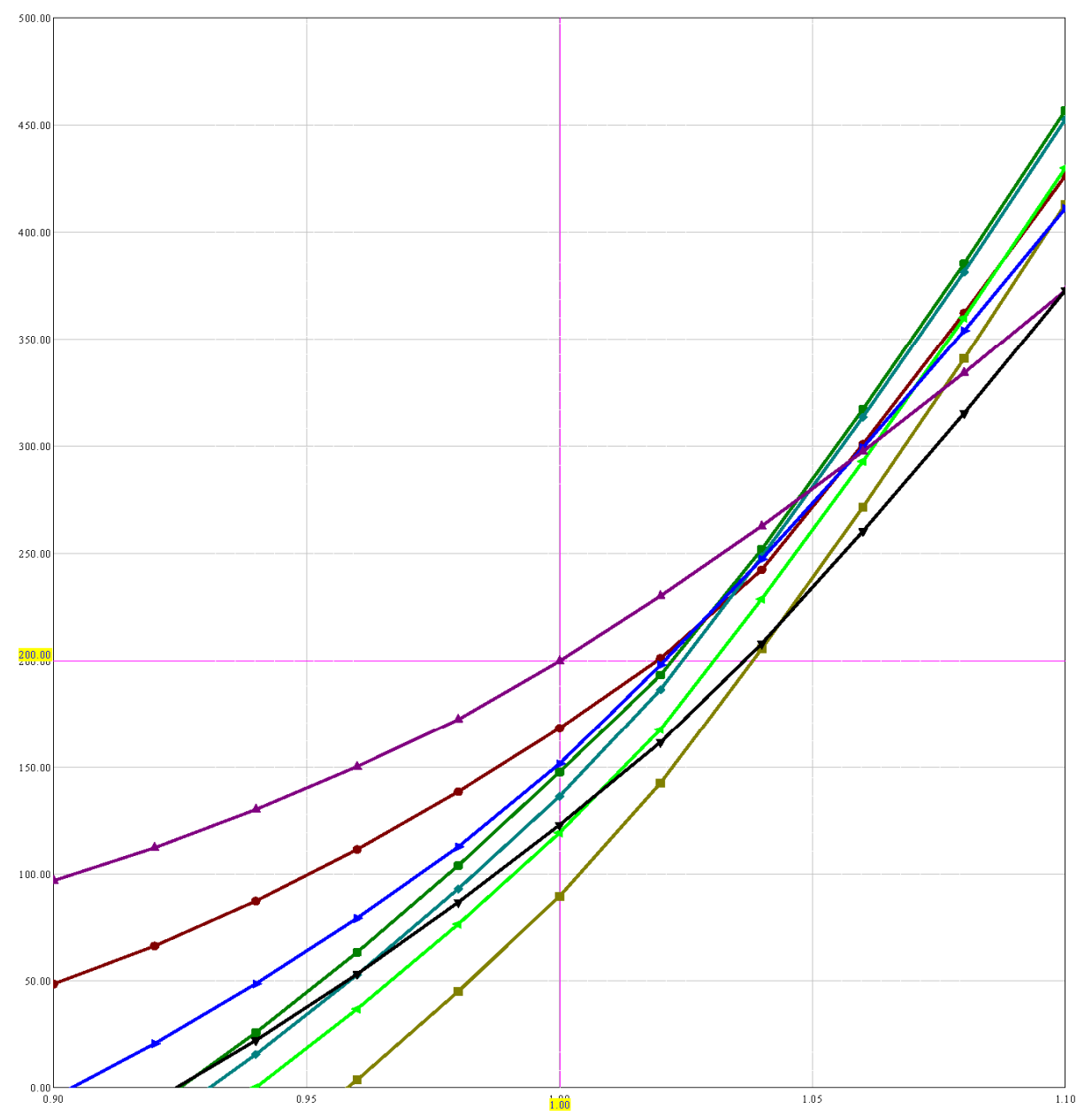

Mark Description study bus: 5400

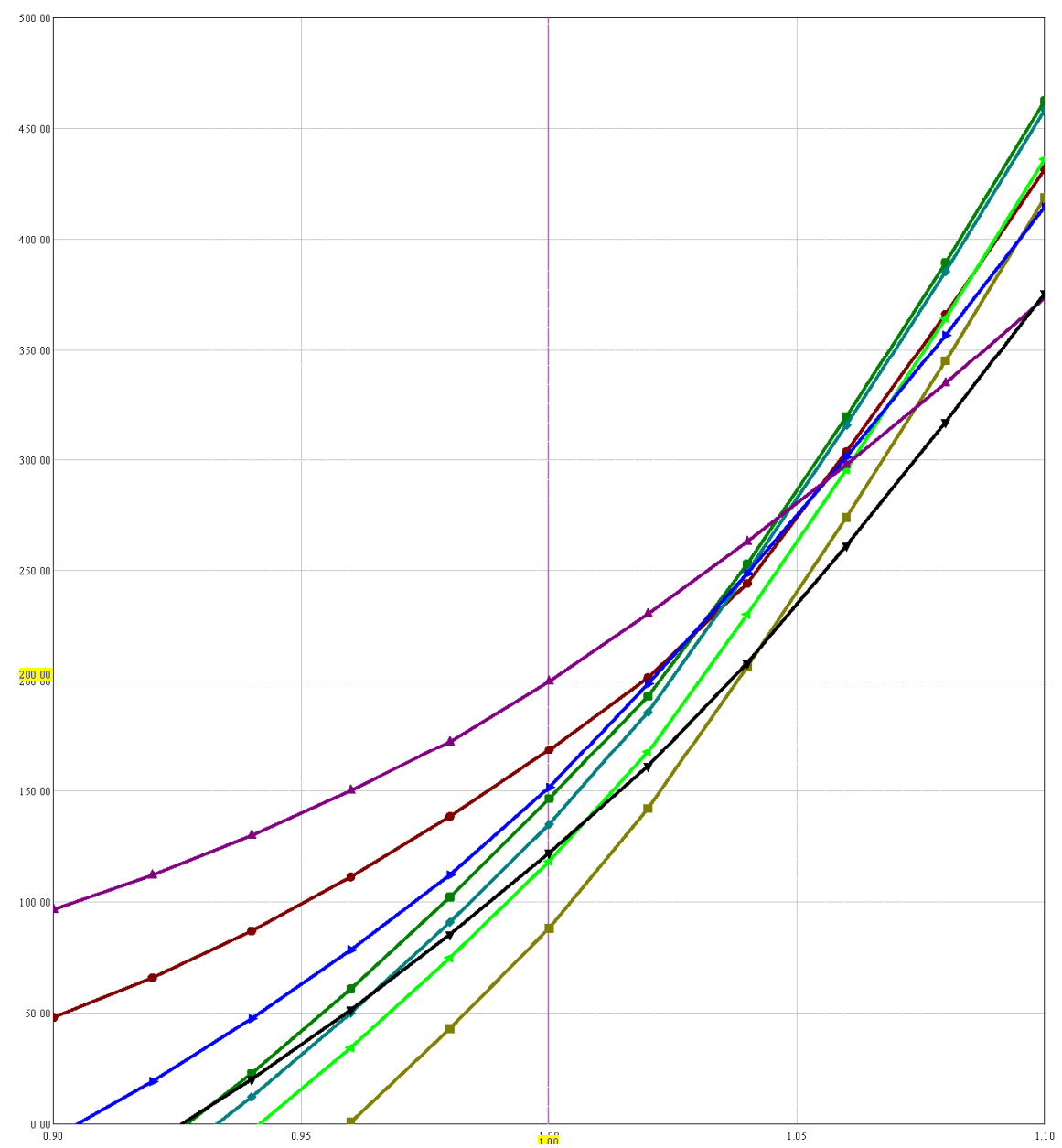

—- - - DASE CASE $\longrightarrow$ - - CPEN LINE FROM BUS 1 [H-DAM500 500.00] TO BUS 490 [H-DAM220 220.00] TO BUS 311 [TER-HD 11.000] CKT 1 $\longrightarrow$ OPEN LNE FROM BUS 506 [QUENA220 220.00] TO BUS 22220 [NAG HAM IND 220.00] CKT $\longrightarrow$ OPEN LINE FROM BUS 586 [A.DAM220 220.00] TO BUS 609 [WAD.NOKR220 220.00] CKT 2 2
2

Figure 7 QV - Analysis results 
the power factor range of between 0.95 lagging to 0.95 leading, as shown in Figure 10i.e. it can inject or absorb reactive power to/from the grid as per the set point from the grid operator even in the night mode[23]. The reactive power support could reach about $30 \%$ of the active power. Hence, the required MVAR could be obtained by operating the Benban PV generators at an appropriate power factor (i.e. any value between 0.95 lagging and unity). For example, the units are operating at 0.9875 power factor lagging.

After applying a new power factor set point of 0.9875 , the PV units will produce reactive power of about 8 MVAR for each unit of $50 \mathrm{MW}$ and this will solve the undervoltage violations.Table 4 includes the voltage levels at several buses close to Benban site before and after applying the new power factor set point at normal case $(\mathrm{N}$ 0 ) (Figure 8) and critical contingency case (N-1) (Figure 9).

Now, we can consider that alternative two is satisfying all grid code requirements. Thus, this alternative is accepted technically but still there is an issue concerning with its cost, because of its weight, the steel structures will be replaced. So, we need to use another conductor which has equal or higher current carrying rating with the same weight as the existing conductors to avoid losing of the steel structures.

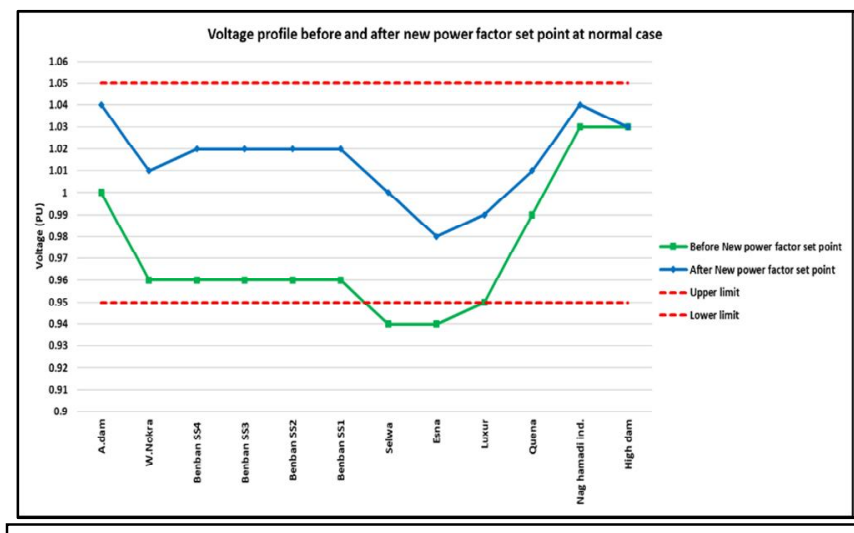

Figure 8 Effect of new power factor set point on the voltage profile in normal case

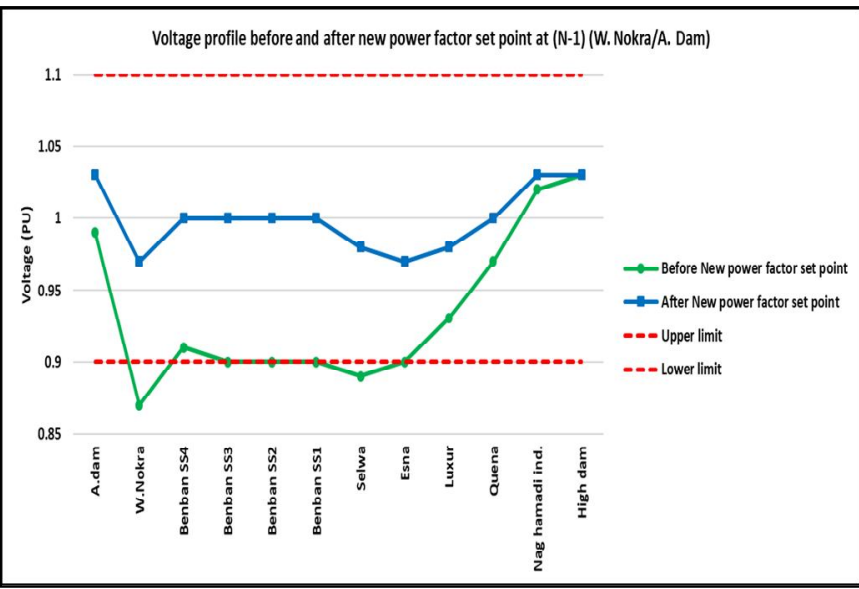

Figure 9 Effect of new power factor set point on the voltage profile in case of (N-1): Disconnect the CKT (W. Nokra/A. Dam)

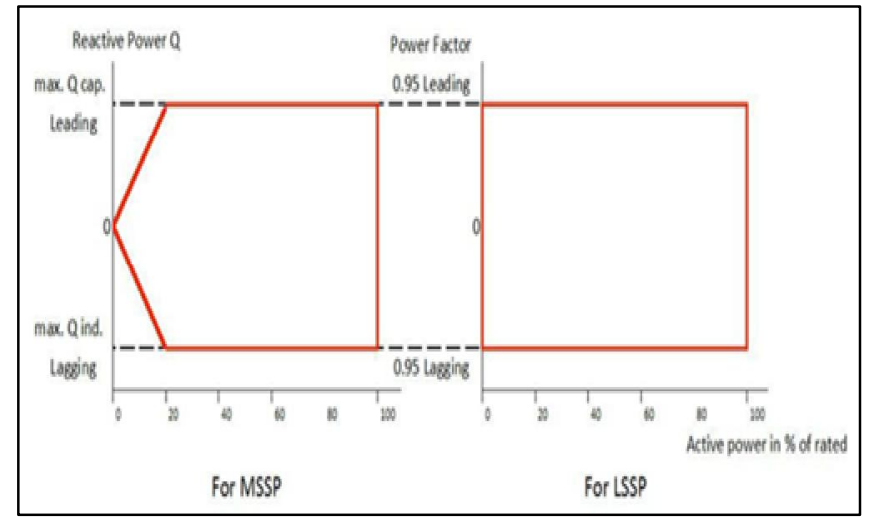

Figure 10Reactive power requirements

Table 3QV-Analysis Results

\begin{tabular}{|l|c|c|c|}
\hline \multirow{2}{*}{ Description } & \multicolumn{3}{|c|}{ Required reactive power (MVAR) } \\
\cline { 2 - 4 } & Bus 5200 & Bus 508 & Bus 5400 \\
\hline Base case & 90 & 110 & 88 \\
\hline $\begin{array}{l}\text { Disconnect one of } \\
\text { 500/220kV transformers of } \\
\text { High Dam SS }\end{array}$ & 170 & 175 & 168 \\
\hline $\begin{array}{l}\text { Disconnect one 220kV Ckt } \\
\text { of (Benban SS4/A. Dam) }\end{array}$ & 200 & 210 & 200 \\
\hline $\begin{array}{l}\text { Disconnect one 500kV Ckt } \\
\text { of (High Dam/Nag. }\end{array}$ & 150 & 166 & 146 \\
Hamadi ind.) & 135 & 160 & 135 \\
\hline $\begin{array}{l}\text { Disconnect one 220kV Ckt } \\
\text { of (Nag. Hamadi ind./S. } \\
\text { Qena) }\end{array}$ & 120 & 145 & 118 \\
\hline $\begin{array}{l}\text { Disconnect one 220kV Ckt } \\
\text { of (Selwa /Benban SS1) }\end{array}$ & 152 & 160 & 152 \\
\hline $\begin{array}{l}\text { Disconnect one 220kV Ckt } \\
\text { of (Benban SS4/W. Nokra) }\end{array}$ & 125 & 140 & 122 \\
\hline $\begin{array}{l}\text { Disconnect one 220kV Ckt } \\
\text { of (W. Nokra/A. Dam) }\end{array}$ & & & \\
\hline
\end{tabular}

Table 4 Effect of new power factor set point on the voltage profile in $(\mathrm{N}-0)$ and $(\mathrm{N}-1)$

\begin{tabular}{|l|c|c|c|c|c|}
\hline \multirow{2}{*}{ Description } & \multirow{2}{*}{$\mathrm{kV}$} & \multicolumn{4}{|c|}{ Busbar voltage (PU) } \\
\cline { 3 - 6 } & & \multicolumn{2}{|c|}{ Normal case (N-0) } & \multicolumn{2}{c|}{$\begin{array}{c}\text { N-1) (W. } \\
\text { Nokra/A. Dam) }\end{array}$} \\
\cline { 3 - 6 } & & Before & After & Before & After \\
\hline A.dam & 220 & 1 & 1.04 & 0.99 & 1.03 \\
\hline W. Nokra & 220 & 0.96 & 1.01 & 0.87 & 0.97 \\
\hline Benban SS4 & 220 & 0.96 & 1.02 & 0.91 & 1 \\
\hline Benban SS3 & 220 & 0.96 & 1.02 & 0.9 & 1 \\
\hline Benban SS2 & 220 & 0.96 & 1.02 & 0.9 & 1 \\
\hline Benban SS1 & 220 & 0.96 & 1.02 & 0.9 & 1 \\
\hline Selwa & 220 & 0.94 & 1 & 0.89 & 0.98 \\
\hline Esna & 220 & 0.94 & 0.98 & 0.9 & 0.97 \\
\hline Luxur & 220 & 0.95 & 0.99 & 0.93 & 0.98 \\
\hline Quena & 220 & 0.99 & 1.01 & 0.97 & 1 \\
\hline $\begin{array}{l}\text { Nag Hamadi } \\
\text { ind. }\end{array}$ & 500 & 1.03 & 1.04 & 1.02 & 1.03 \\
\hline High Dam & 500 & 1.03 & 1.03 & 1.03 & 1.03 \\
\hline
\end{tabular}




\subsubsection{Alternative 3:}

Here, the conductors of the OHTL (Selwa/W.Nokra/A.dam) will be replaced by (Thermal STACIR $2 * 238 / 97$ ) with the capacity of 914 MVA but with the same weight as the existing conductors (ACSR $2 * 380 / 50 \mathrm{~mm} 2)$. The Benban PV units are assumed to operate at power factor of 0.9875 lagging from day one. The results for $(\mathrm{N}-0)$ in this alternative are better than those of the last alternative. The results show that there is neither overloading violations nor voltage violations in the normal condition. Also, the results of the contingency analysis are much better than those of the last alternative. All under voltage and over loading violations are disappeared.

Based on the above, it is seen obviously that this alternative is satisfying the grid code requirements with respect to both the equipment's loading and voltage profile.
Table 6and Figure 12contains a comparison between the three alternatives with respect to the equipment's' loadings

\subsubsection{Estimated cost for the three alternatives:}

- Reference Cost

- $220 \mathrm{kV}(\mathrm{D} / \mathrm{Cs}) \mathrm{TL}$, bundle of two $\left(2 * 380 / 50 \mathrm{~mm}^{2}\right.$ ACSR), 4 Million EGP/KM.

- $220 \mathrm{kV}(\mathrm{D} / \mathrm{Cs}) \mathrm{TL}$, bundle of three $\left(3 * 380 / 50 \mathrm{~mm}^{2}\right.$ ACSR), 6 Million EGP/KM.

- $\quad 220 \mathrm{kV}$ (D/Cs) TL, bundle of two (STACIR thermal), 5 Million EGP/KM.

- Reconductoring 220kV (D/Cs) TL, bundle of two (STACIR thermal), 1 Million EGP/KM.

- 220/22/22kV substation (4*175 MVA), 400 Million EGP.

- Table 5andFigure 11 shows the estimated cost comparison between three alternatives

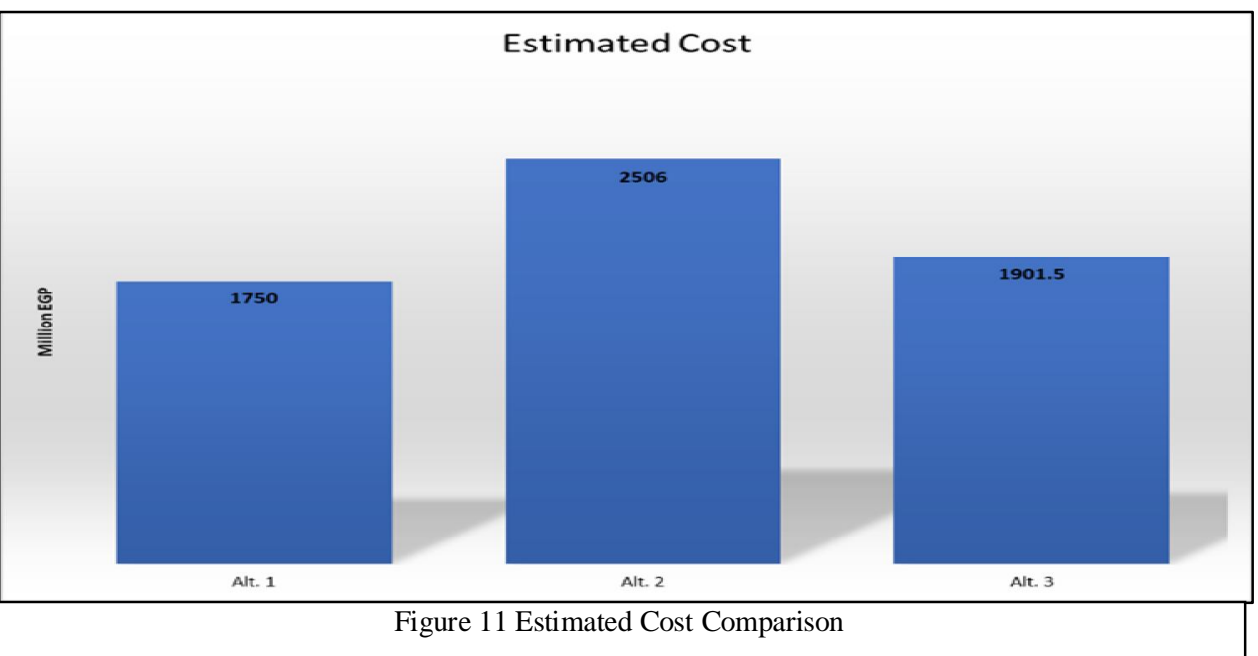

Table 5Estimated Cost

\begin{tabular}{|l|c|c|c|c|}
\hline \multirow{2}{*}{ Item } & \multirow{2}{*}{ Amount } & \multicolumn{2}{c|}{ Total cost (Million EGP) } \\
\cline { 3 - 5 } & & Alt. 1 & Alt. 2 & Alt. 3 \\
\hline $\begin{array}{l}\text { Construction of four substations (Benban } \\
\text { SS1:SS4) 220/22/22 kv with 4*175 MVA } \\
\text { transformers }\end{array}$ & 4 & 1600 & 1600 & 1600 \\
\hline Double CKT (Selwa/opening point) & 45 & --- & 270 & 45 \\
\hline Double CKT (opening point/SS1) & 15 & 60 & 90 & 75 \\
\hline Double CKT (SS1/SS2) & 3.5 & 14 & 21 & 17.5 \\
\hline Double CKT (SS2/SS3) & 2 & 8 & 12 & 10 \\
\hline Double CKT (SS3/SS4) & 2 & 8 & 12 & 10 \\
\hline Double CKT (SS4/ opening point) & 15 & 60 & 90 & 75 \\
\hline Single CKT (opening point/W. Nokra) & 21 & --- & 63 & 11 \\
\hline Single CKT (opening point/A. Dam) & 50 & --- & 150 & 25 \\
\hline Single CKT (W. Nokra /A. Dam) & 66 & --- & 198 & 33 \\
\hline \multicolumn{1}{|c|}{ Total cost } & & 1750 & 2506 & 1901.5 \\
\hline
\end{tabular}


Table 6 Equipment loading comparison for three alternatives

\begin{tabular}{|c|c|c|c|c|c|c|}
\hline \multirow[b]{2}{*}{$\#$} & \multirow[b]{2}{*}{ Event } & \multirow[b]{2}{*}{ Description } & \multirow[b]{2}{*}{ kV } & \multicolumn{3}{|c|}{ The second CKT/ Trans. loading (\%) } \\
\hline & & & & $\begin{array}{l}\text { Alternative } \\
\text { (1) }\end{array}$ & $\begin{array}{l}\text { Alternative } \\
\text { (2) }\end{array}$ & $\begin{array}{l}\text { Alternative } \\
\text { (3) }\end{array}$ \\
\hline 1. & $\mathrm{~N}-1$ & $\begin{array}{l}\text { Disconnect one of } 500 / 220 \mathrm{kV} \\
\text { transformers of Nag. Hamadi ind. }\end{array}$ & 500 & 78.5 & 78 & 70.9 \\
\hline 2. & $\mathrm{~N}-1$ & $\begin{array}{l}\text { Disconnect one Ckt of (Nag. Hamadi } \\
\text { ind./S. Qena) }\end{array}$ & 220 & 80 & 78 & 71.7 \\
\hline 3. & $\mathrm{~N}-1$ & $\begin{array}{l}\text { Disconnect one Ckt of (S. Qena / Luxur } \\
\text { East) }\end{array}$ & 220 & 43.7 & 40 & 31.8 \\
\hline 4. & $\mathrm{~N}-1$ & Disconnect one Ckt of (Luxur East / Isna) & 220 & 47.8 & 47.4 & 42.4 \\
\hline 5. & $\mathrm{~N}-1$ & Disconnect one Ckt of (Isna /Selwa) & 220 & 70 & 69.8 & 68.4 \\
\hline 6. & $\mathrm{~N}-1$ & $\begin{array}{l}\text { Disconnect one Ckt of (Selwa / Benban } \\
\text { SS1) }\end{array}$ & 220 & 107 & 71.4 & 51.3 \\
\hline 7. & $\mathrm{~N}-1$ & $\begin{array}{l}\text { Disconnect one Ckt of (Benban SS1 } \\
\text { / Benban SS2) }\end{array}$ & 220 & 63.7 & 42.3 & 30 \\
\hline 8. & $\mathrm{~N}-1$ & $\begin{array}{l}\text { Disconnect one Ckt of (Benban SS2 } \\
\text { / Benban SS3) }\end{array}$ & 220 & 24.8 & 16.5 & 7.4 \\
\hline 9. & $\mathrm{~N}-1$ & $\begin{array}{l}\text { Disconnect one Ckt of (Benban SS3 } \\
\text { / Benban SS4) }\end{array}$ & 220 & 60 & 40.5 & 23.7 \\
\hline 10. & $\mathrm{~N}-1$ & $\begin{array}{l}\text { Disconnect the Ckt (Benban SS4/W. } \\
\text { Nokra) }\end{array}$ & 220 & 108.8 & 73.8 & 44.9 \\
\hline 11. & $\mathrm{~N}-1$ & Disconnect the Ckt (W. Nokra/A. Dam) & 220 & 92.6 & 62.5 & 32.8 \\
\hline 12. & $\mathrm{~N}-1$ & Disconnect one Ckt of (A. Dam/High Dam) & 220 & 87 & 86.3 & 52.8 \\
\hline 13. & $\mathrm{~N}-1$ & $\begin{array}{l}\text { Disconnect one Ckt of (High Dam/Nag. } \\
\text { Hamadi ind.) }\end{array}$ & 500 & 64.6 & 64.8 & 63.1 \\
\hline 14. & $\mathrm{~N}-1$ & $\begin{array}{l}\text { Disconnect one Ckt of (Nag. Hamadi } \\
\text { ind./Nag. Hamadi) }\end{array}$ & 500 & 45.5 & 45.7 & 45.2 \\
\hline 15. & $\mathrm{~N}-1$ & $\begin{array}{l}\text { Disconnect one Ckt of (Nag. Hamadi } \\
\text { ind./Qena East) }\end{array}$ & 500 & 17.7 & 17.7 & 17.2 \\
\hline
\end{tabular}

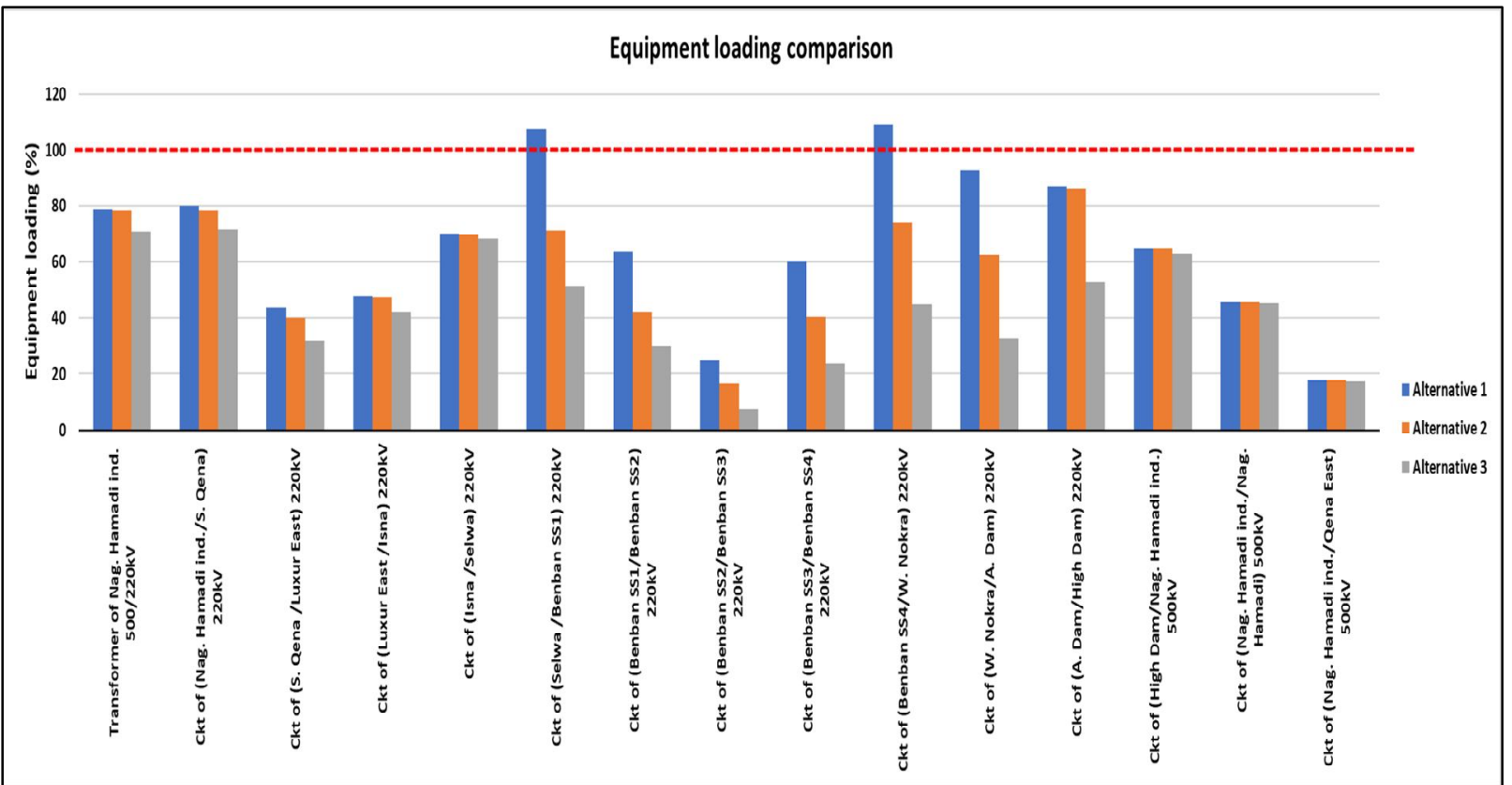

Figure 12 Equipment loading comparison 


\section{CONCLUSION}

Egyptian Electricity Transmission Company (EETC) has a plan for the renewable generation to be about $20 \%$ of installed generation capacity (mainly PV and wind) by 2022. This paper is conducted to ensure that the Egyptian power system is capable to evacuate the renewable power generated from Benban solar park in safe manner under various operating conditions. The total renewable installed capacity (existing + planned) is expected to be 3209 MW by year 2020. A 1409 MW out of 3209 MW are wind power located in the Gabal El-Zayt and Gulf of Suez Region, the remaining 1800 MW are Solar power located in Benban Region. The study considered the morning peak scenario which represents the most stressful condition of the grid with respect to renewable integration.

Three alternatives are suggested to connect Benban park to the national unified grid as follows:

- Alternative 1: opening the double circuit OHTL $220 \mathrm{kV}$, (ACSR $2 * 380 / 50 \mathrm{~mm}^{2}$ ) (Selwa/W.Nokra/A.dam) line in/out on the Benban solar park substations.

- Alternative 2: opening the double circuit OHTL $220 \mathrm{kV}$ (Selwa/W.Nokra/A.dam) line in/out on the Benban solar park substations after rehabilitating its conductors to be bundle of three (ACSR $3 * 380 / 50 \mathrm{~mm}^{2}$ ).

- Alternative 3: opening the double circuit OHTL $220 \mathrm{kV}$ (Selwa/W.Nokra/A.dam) line in/out on the Benban solar park substations after replacing its conductors with thermal conductors of type (Thermal STACIR 2*238/97 $\mathrm{mm}^{2}$ ).

The steady state results for the first alternative shows that there is no overloading under normal operating conditions $(\mathrm{N}-0)$ but, there are some minor voltage violations at Esna and Selwa substations as the voltages reach to 0.94 pu (about $206 \mathrm{kV}$ ). However, the contingency analysis shows several overloading violations, due to Benban integration. The critical contingency events are at the $220 \mathrm{kV}$ transmission system of high dam and Benban area.

The steady state results for the second alternative shows that there is no overloading under normal operating conditions $(\mathrm{N}-0)$ but, there are also some minor voltage violations. the contingency analysis (N-1) is conducted and the results show that the main overloading bottlenecks appeared in the first alternative are eliminated here but still some under voltage violations and blown-up cases.

the reactive power requirements study (QV-Analysis) shows that there is a need for certain amount of MVAR to be injected at Benban nearby substations to overcome the under voltage violations results from the critical contingency cases and blown up cases and this MVAR could be obtained from changing the power factor set point at which the PV units are working, so that changing of the generators power factor set point leads to solve the under voltage violations and makes the second alternative is accepted technically, but still there are a problem for executing this alternative concerning with the conductor weight. The heavy weight of about 4360 $\mathrm{kg} / \mathrm{km}$ cannot be suspended to the same towers and steel structures designed to carrythe original conductors' weight not more than $3000 \mathrm{~kg} / \mathrm{km}$, so that the steel structures and all towers should be replaced which means very high cost.

Hence, a third alternative should be proposed to have an accepted solution technically and financially, the conductors used in the third alternative are lighter than those of the second alternative with high thermal rate, weight of 2900 $\mathrm{kg} / \mathrm{km}$ and rate of 914 MVA, the results show that there is neither overloading violations nor voltage violations in the normal condition. Also, the results of the contingency analysis are much better than those of the last alternative. All under voltage and over loading violations are disappeared.

the steady state analysis shows that the optimum alternative to evacuate $1000 \mathrm{MW}$, representing stage one of Benban park, is by means of opening the double circuit OHTL 220 $\mathrm{kV}$ (Selwa/W.Nokra/A.dam) line in/out on the Benban solar park substations after replacing its conductors with thermal conductors of type (Thermal STACIR $2 * 238 / 97 \mathrm{~mm}^{2}$ ). This alternative satisfies all the grid codes requirements and also is accepted technically and financially.

\section{REFERENCES}

[1] NREA, "Renewable Energy Annual Report," pp. 337, 2018.

[2] "Global Solar Market: Top 10 Trends in 2019 | Verisk Analytics," 2019. https://www.verisk.com/verisk-review/summer2019/global-solar-market-top-10-trends-in-2019/ (accessed Apr. 10, 2020).

[3] M. E. Solar, "Solar Outlook Report 2020," 2020.

[4] "Solar energy." https://www.irena.org/solar (accessed Apr. 25, 2020).

[5] A. M. Baniyounes, "Renewable energy potential in Jordan," Int. J. Appl. Eng. Res., vol. 12, no. 19, pp. 8323-8331, 2017.

[6] Y. Al-Douri, S. A. Waheeb, and C. H. Voon, "Review of the renewable energy outlook in Saudi Arabia," J. Renew. Sustain. Energy, vol. 11, no. 1, 2019, doi: 10.1063/1.5058184.

[7] New \& Renewable Energy Authority Egypt, "Strategic Environmental \& Social Assessment Final Report," no. February, pp. 1-220, 2016, [Online]. Available:

https://www.miga.org/sites/default/files/archive/Doc uments/SPGDisclosures/Benban Strategic Environmental and Social Assessment- Feb2016 Final Report.pdf.

[8] U. A. Rahoma, A. H. Hassan, Y. A. Abdel-Hadi, and A. Abulwfa, "An optimization approach of hybrid PV-wind renewable energy systems for power generation in Egypt," Sustain. Dev. Plan. VIII, vol. 1, no. September 2017, pp. 541-552, 2016, doi: 10.2495/sdp160451.

[9] J. P. Mortensen, Niels Gylling; Said Said, Usama; Badger, "Wind Atlas for Egypt - DTU Orbit," Proc. Third Middle East-North Africa Renew. Energy Conf., pp. 1-13, 2006, [Online]. Available: http://orbit.dtu.dk/en/publications/wind-atlas-foregypt(82b21275-cc36-440a-b180-3434c2c9621c).html. 
[10] N. G. Mortensen et al., "Wind atlas for Egypt: Measurements, micro-and mesoscale modelling," Eur. Wind Energy Conf. Exhib. 2006, EWEC 2006, vol. 1, pp. 136-145, 2006.

[11] IRENA, Renewable Energy Outlook: Egypt. 2018.

[12] EEHC, “Annual report 2017/2018," 2018.

[13] EEHC, “Annual Report 2013-2014.pdf.” 2014.

[14] EEHC, "Ministry of Electricity \& Energy 2015, The Annual Report of 2014/2015," vol. 2015, 2015, [Online]. Available: http://www.moee.gov.eg/english_new/EEHC_Rep/20 14-2015en.pdf.

[15] EEHC, "Egyptian Electricity Holding Company (EEHC) Annual report 2015/2016,” p. 64, 2016.

[16] EEHC, "Annual Report of Egypt Electricity 2016/2017," Egypt. Electr. Hold. Co., pp. 1-46, 2017, [Online]. Available: http://www.eehc.gov.eg/.

[17] EEHC, "EEHC annual report 2018/2019," no. 1, pp. 6-8, 2019.

[18] "Projects | Multilateral Investment Guarantee Agency | World Bank Group." https://www.miga.org/projects?host_country\%5B\%5 $\mathrm{D}=373$ \&project_status=All\&env_category=All\&proj ect_type=All\&board_date $\% 5 \mathrm{Bmin} \% 5 \mathrm{D}=\&$ board_dat e $\% 5 \mathrm{Bmax} \% 5 \mathrm{D}=\&$ title $=\&$ project_id $=($ accessed May 16, 2020).

[19] EETC, "SECTION 2 CONNECTION CODE," pp. $1-27$.

[20] EETC, "SECTION 6 PLANNING CODE."

[21] EETC, "SECTION 7 OPERATION CODE," pp. 118.

[22] EETC, "SECTION 5 Performance Code," Thinking, vol. 4, no. September, pp. 1-120, 2007.

[23] Egyptian transmission grid code, "Solar Energy Plants Grid Connection Code," no. March, p. 30, 2017, [Online]. Available: http://egyptera.org/Downloads/code w dalil/code/Egypt_gridcode_for_solar_plant_connecti on on MV and HV.pdf. 